\title{
ERROR ASSESSMENT IN FORECASTING CRYPTOCURRENCIES TRANSACTION COUNTS USING VARIANTS OFTHE GREY LOTKA-VOLTERRA DYNAMICAL SYSTEM
}

\author{
Paul Gatabazi ${ }^{1}$, Jules $\mathrm{Mba}^{1}$, and Edson Pindza ${ }^{2}$ \\ ${ }^{1}$ University of Johannesburg \\ ${ }^{2}$ University of Pretoria
}

September 27, 2020

\begin{abstract}
The error assessment is made on the classical Grey Model $(\operatorname{GM}(1,1))$ and the variants of Grey Lotka-Volterra dynamical system namely the Grey Lotka-Volterra Model (GLVM), the Fractional Grey Lotka-Volterra Model (FGLVM) and the Variable-order Fractional Grey Lotka-Volterra Model (VFGLVM) for modeling the transaction counts of three selected cryptocurrencies in 2-and 3-dimensional framework. Bitcoin, Litecoin and Ripple. The cryptocurrencies of interest are Bitcoin, Litecoin and Ripple. The 2-dimensional models use Bitcoin and Litecoin transactions from April, 28, 2013 to February, 10, 2018. The 3-dimensional model uses transactions of Bitcoin, Litecoin and Ripple from August, 7, 2013 to February, 10, 2018. The error sequence patterns and the the Mean Absolute Percentage Error (MAPE) suggest a relatively higher accuracy of the VFLVM in 2- and 3-dimensional study.
\end{abstract}

\section{Hosted file}

PMP4.pdf available at https://authorea.com/users/362226/articles/483450-error-assessmentin-forecasting-cryptocurrencies-transaction-counts-using-variants-ofthe-grey-lotkavolterra-dynamical-system 

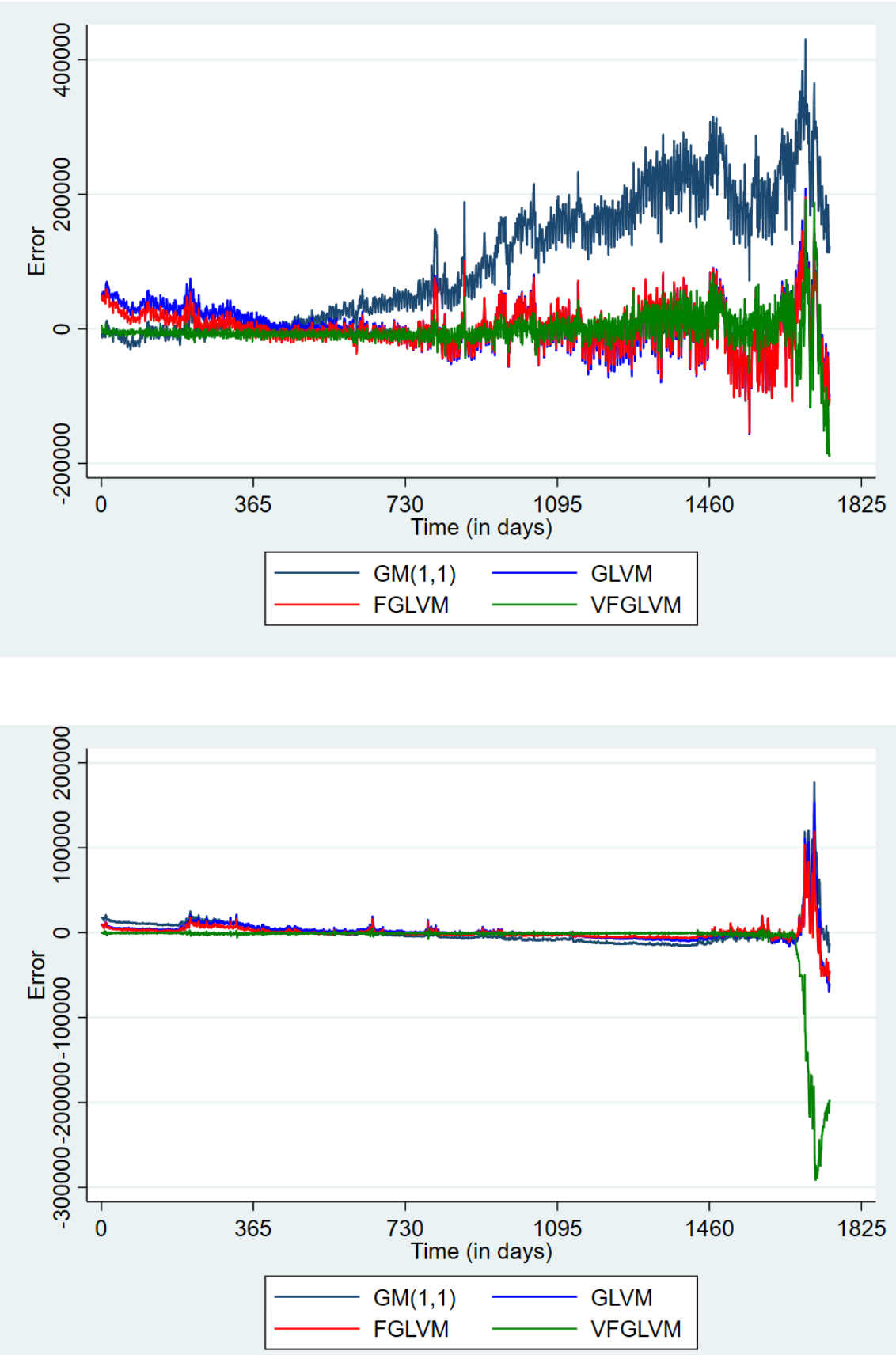

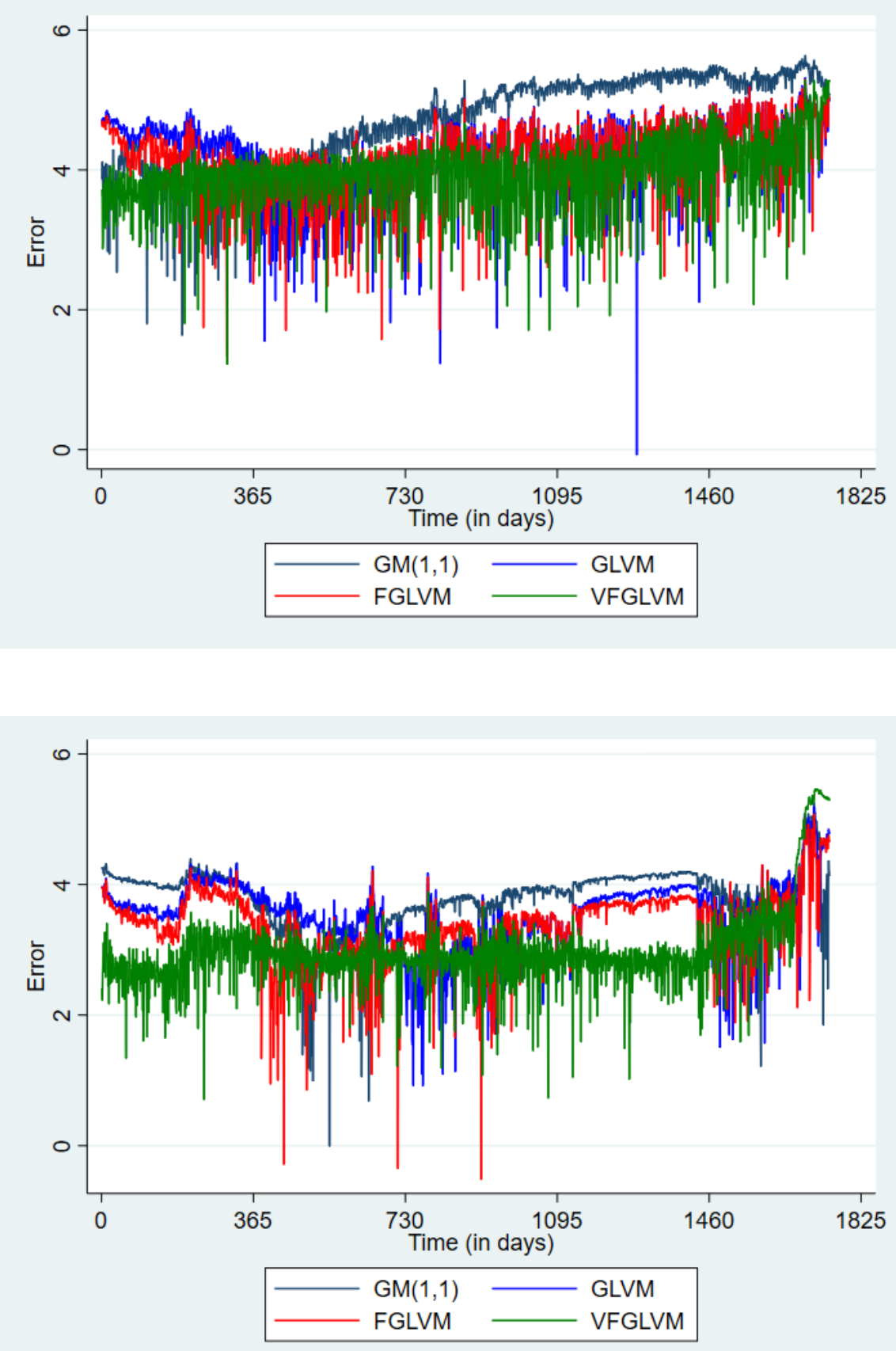

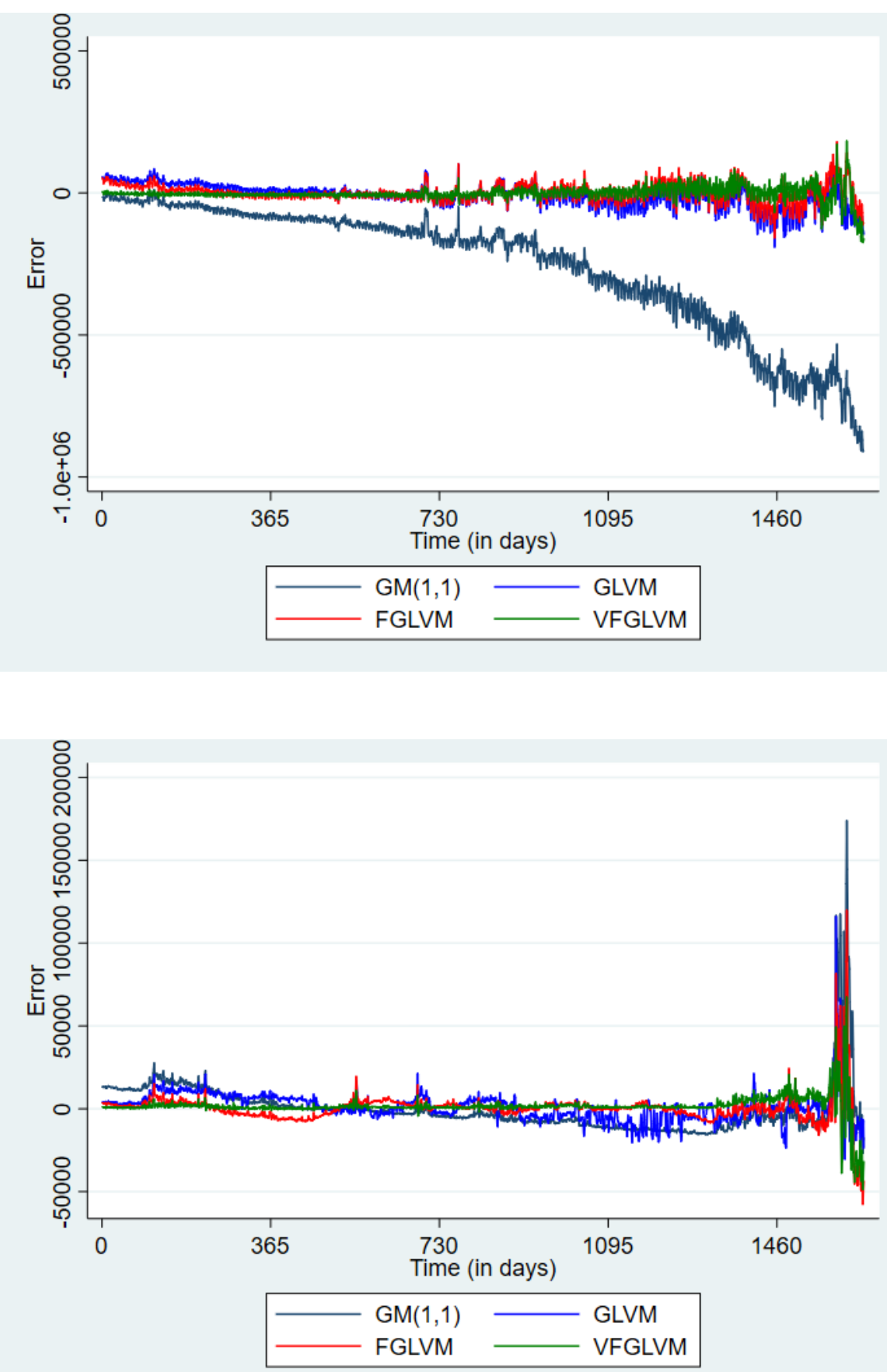

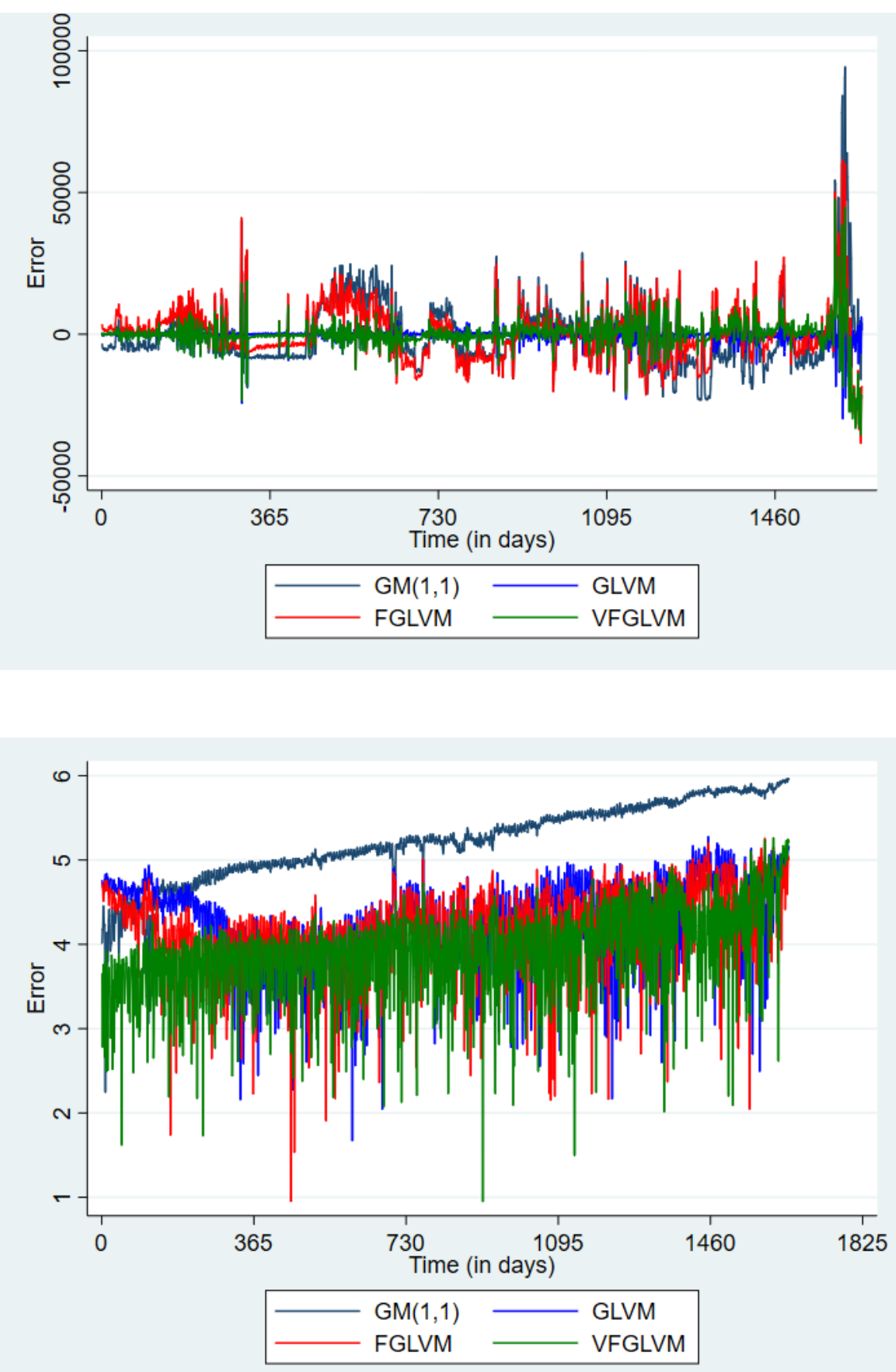

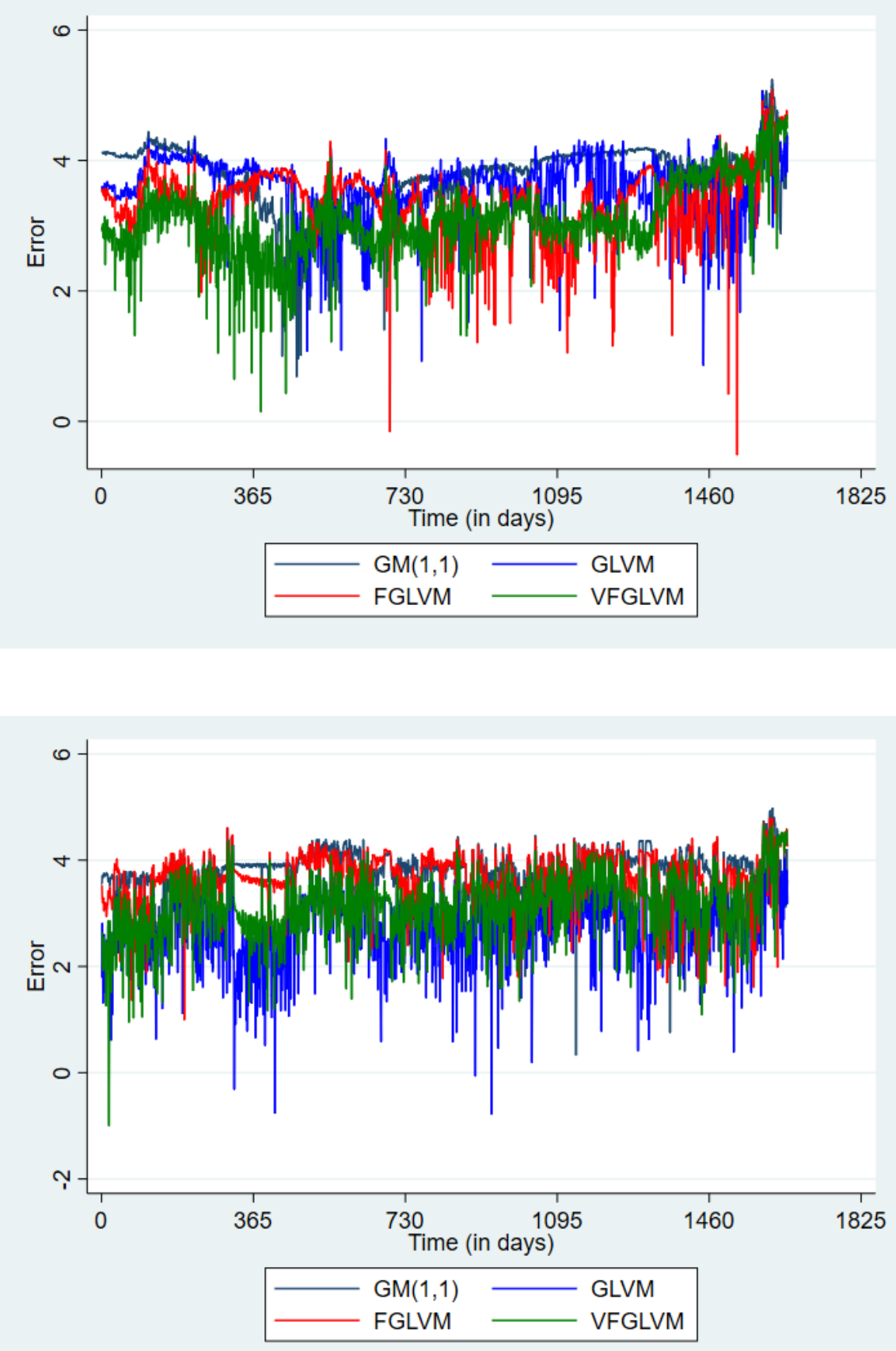